\title{
The relationships between triarchic psychopathic traits and value orientations in men and women
}

\author{
Tajana Ljubin-Golub ${ }^{1}$ \\ University of Zagreb, Faculty of Teacher Education, Croatia
}

\section{Katarina Sokić}

University College Effectus, College for Finance and Law, Zagreb, Croatia

\begin{abstract}
This study was aimed to explore the relationship between triarchically conceptualized psychopathic traits and different value orientations. Participants were 180 male and 216 female Croatian university students. Self-report data were collected by using the Triarchic Psychopathy Measure (TriPM) and Value Orientation Scale. As predicted, meanness was negatively related to conventional and self-realization value orientation, and positively to hedonistic value orientation in both men and women, thus suggesting that meanness is the central component of psychopathy operating similarly across gender. Additionally, the results revealed some gender differences in the role of triarchic psychopathy components in value acquisition. In women's sample only, hedonistic value orientation was related to higher boldness and higher disinhibition. Only in men's sample, several interactions were found between psychopathic components predicting value orientations. The negative effect of disinhibition on self-realization and conventional values was more pronounced when associated with high boldness. In addition, the negative effect of disinhibition on the acquisition of self-realization values emerged only under the high meanness conditions, while the opposite trend was demonstrated for low meanness condition. Thus, gender moderated some of the psychopathy-values relationship, although this effect was small.
\end{abstract}

Key words: psychopathy, values, hedonistic, conventional, self-realization, gender differences

\section{Introduction}

\subsection{Triarchic psychopathy}

There is a rich tradition in psychology of the study of personality deviations, and, in particular, psychopathy. Accordingly, several conceptualizations of psychopathy were proposed, among which the most prominent were Cleckley's

1 tajana.ljubingolub@ufzg.hr 
(1976) conception of psychopatic personality, and Hare's (2003) operationalization of psychopathy.

A novel conceptualization of psychopathy, the Triarchic Psychopathy Model (TPM) was proposed by Patrick, Fowles, \& Krueger (2009). According to this model, psychopathy encompasses three distinct, elemental phenotypic constructs with psychological and neurobiological correlates, i.e. boldness, meanness and disinhibition. Boldness reflects a syndrome of social dominance, emotional resilience, venturesomeness, and high social efficacy. Boldness was found to be associated with socially adaptive characteristics, comprising persuasiveness, stress immunity, and well-being, while, on the other hand, boldness is associated also with maladaptive tendencies, such as grandiosity, risk taking, dishonesty, guiltlessness, and emotional insensitivity (Drislane, Patrick, \& Arsal, 2014; Marion et. al., 2012; Sellbom \& Phillips, 2013; Stanley, Wygant, \& Sellbom, 2013). Boldness is thought to form a psychopathic personality only when in combination with either disinhibition or meanness. Meanness is defined as aggressive resource seeking without regard for others (Patrick et al., 2009). Meanness captures the tendencies towards callousness, aggressiveness, machiavellianism, and remorselessness (Patrick, Drislane, \& Strickland, 2012). Disinhibition refers to a general propensity towards the problems of impulse control, including both impaired regulation of affect and urges and impaired behavioural restraint. Disinhibition of affect includes impulsivity and negative affectivity, while behavioural disinhibition includes aggressive acting out, proneness to drug and alcohol misuse, and norm-breaking behaviour (Patrick et al., 2009). Generally, the study of psychopathy both in adults and adolescents has focused predominantly on the samples with conduct deviance. Only recently, while measures were developed to study subclinical psychopathy, i.e. psychopathic traits in normal population, the studies researching psychopathy in non-delinquent youth have starting to emerge (e.g. Poy, Segarra, Esteller, López, \& Moltó, 2014; Blagov, Patrick, Oost, Goodman, \& Pugh, 2016). However, according to the best knowledge of the authors, there is no study on the relationship between triarchic psychopathic traits and values.

\subsection{Values}

Values represent what people believe is personally important to guide their lives (Schwartz, 1994; Schwartz \& Bilsky, 1990), and serve as norms or criteria for guiding our thoughts and actions. There are several operationalizations of values in the literature, with the most widely used model of values being the Schwartz's model (1992). This model identifies 10 universal social values such as security, tradition, conformity, benevolence, universalism, selfdirection, stimulation, hedonism, achievement and power. Research done in Croatia resulted in the operationalization of three value orientations, i.e. conventional, self-realization, and hedonistic value orientation (Franc, 
Šakić, \& Ivičić, 2002). According to this conceptualization, the conventional value orientation includes values such as harmonious life with family and friends, helping others, honesty, life consistent with moral and religious principles, good education and contributing to society. The self-realization value orientation captures values such as to love and be loved, the realization of close friendly relations with others, exploring, independence, selfactualization and creativity. Utilitarian-hedonistic orientation encompass values of enjoying life, good salary and high standard of living, life stability and comfort, pleasure and sensuous gratification for oneself, social status and prestige and control or dominance over people (Franc et al., 2002).

The acquisition and maintenance of the values and value orientations is considered to be mainly the result of the process of socialization (Rokeach, 1973), thus being considered largely exogenous. However, once adopted, values are theorized to be stable, although they can be reprioritized based on the former experience and social expectations (Bilsky \& Schwartz, 1994). Since values are considered to be the result of the socialization process (Rokeach, 1973), several authors have suggested that personality variables, which are largely endogenous, are antecedents of values (e.g. Roccas, Sagiv, Schwartz, \& Knafo, 2002).

Although values are conceptually different from traits, they are empirically associated, i.e. have significant common variance (e.g. Roccas et al., 2002). Not surprisingly, the relationship between personality and values has been fairly investigated. Recent meta-analysis of the relationships between the Five factor model of personality traits and the Schwartz values (ParksLeduc, Feldman, \& Bardi, 2015) showed that more cognitively based traits demonstrate stronger relationships with values, and more emotionally based traits exhibit weaker (or no) relationships with values.

Since psychopathy encompasses immoral behaviour (Glen, Koleva, Iyer, Graham, \& Ditto, 2010), studying the relationship between psychopathic traits and values is particularly important for understanding human behaviour and the moral development of the society (Buckels, Trapnell, \& Paulhus, 2014; Silfver, Helkama, Lönnqvist, \&Verkasalo, 2008). Additionally, a recent study (Kajonious, Persson, \& Jonason, 2015) has shown that the Dark Triad traits, which include psychopathy, accounted for the unique variance in social values not accounted for by the Big Five. Therefore, it seems that studying the relationship between psychopathic traits and social values is noteworthy.

\subsection{Psychopathy and values}

Although it seems to be an important topic, there is only a limited number of research studies investigating the relationship between psychopathy and values. The research on psychopathy and sexual values, in which psychopathy was measured by Levenson's self-report psychopathy 
scale (LSRP; Levenson et al., 1995), found that psychopathy (as measured by the total score on LSRP) had a positive relationship with hedonistic sexual values (example items for hedonistic sexual values are: "Dating is one of the simple ways to satisfy sexual needs", "There is nothing wrong if one views sex as a source of worldly pleasures") and relativistic sexual values (example item being: "Sexual intercourse with an unsteady partner is feasible as long as promoting safe sexual behaviour"), and a negative relationship with absolute/ conservative/traditional sexual values (example items: "Husband or wife must not have sex with someone else other than their committed partner"; "Sexual relation before marriage is permissive to do" - reversely scored) (Abraham \& Rahardjo, 2015). Kajonius et al. (2015) examined the relationships between the Dark Triad traits, which encompass psychopathy, and values. The results showed that psychopathy was positively associated with power (e.g. prestige, authority, wealth), hedonism (e.g. pleasure, enjoying life), and stimulation (e.g. exciting life, varied life), and negatively with conformity (e.g. obedience, honouring parents) and security. Another study of the relationships between The Dark Triad traits and moral and social values (Jonason, Strosser, Kroll, Duineveld, \& Baruffi, 2015) reported that psychopathy significantly predicted low moral values such as harm (related to virtues of kindness, gentleness, and nurturance), fairness (related to the ideas of justice, rights, and autonomy), and authority (which includes deference to legitimate authority and respect for traditions), and low social values, such as collective interests, selftranscendence, and conservation. A study done by Martin (1985) found that juvenile delinquents with high psychoticism as measured by Eysenck's $\mathrm{P}$ scale (a measure strongly associated with psychopathy) considered as most important the values of having an exciting life, pleasure, and ability. Some studies do not measure psychopathy, but antisocial behaviour, psychopathy correlated behaviour associated primarily with impulsive and disinhibited components of psychopathy (for a review about the neural difference between antisocial behaviour and psychopathy see Blair, 2010). Antisocial behaviour (in institutionalized delinquents and in non-institutionalized delinquents, i.e. adolescents) was found to be associated with hedonistic values and a lack of interest in conventional and social values (Romero, Sobral, Luengo, \& Marzo, 2001; Franc et al., 2002). However, it is not known what the role of triarchically conceptualized psychopathy in value dimensions is. More specifically, there is no published study available that has examined the hypotheses underlying the triarchic conceptualization of psychopathy which can elaborate on differences between boldness, meanness and disinhibition in relation to values.

\subsection{Gender differences in psychopathy and values}

Generally, there is the scarcity of studies investigating psychopathic traits in relation to females compared with males (e.g. Verona \& Vitale, 2006). The existing ones usually show profound gender differences in the mean level of 
psychopathy (e.g. de Vogel \& Lancel, 2016). Additionally, since men tended to be undersocialized and women tended to be oversocialized, it may be that at least some psychopathic traits in women may manifest differently. In line with that, it was found that psychopathy in men compared to women was more associated with antisocial behaviour (Strand \& Belfrage, 2005), violence and criminal recidivism (Verona \& Vitale, 2006), as well as with impulsivityrelated tendencies (e.g., difficulties resisting urges, sensation seeking) (Miller, Watts, \& Jones, 2011). In contrast, psychopathy in women was associated with more fraud in criminal history, manipulative and self-destructive behaviour during therapy (de Vogel \& Lancel, 2016), and internalizing symptoms such as depression (Sevecke, Lehmkuhl, \& Krischer, 2009). There are also gender differences in values with females reporting lower hedonistic values (Abraham \& Rahardjo, 2015).

With regard to triarchic psychopathy, only some studies reported on gender comparisons (e.g. Sica et al., 2015; Poy et al., 2014), and showed that men had higher levels of meanness and boldness components of psychopathy (Drislane \& Patrick, 2016). Also, there is the scarcity of studies on the moderating effect of gender (Sellbom, Donnelly, Rock, Phillips, \& BenPorath, 2016), while there is no study reporting on the gender as a potentially moderator variable in the psychopathy-value relationship. Thus, investigating gender differences in the triarchic psychopathy-value relationship seems to represent advancement to the literature.

\subsection{The current study}

As seen from the discussion above, it may be theorized that psychopathy is associated with certain value orientations, but there has been only limited research on this topic. Therefore, the current study is aimed at filling this gap by investigating three value orientations in relation to psychopathy. Additionally, potential differences among the three components of psychopathy in relation to values may shed light on the differences between psychopathy domains in the ways that would be predicted based on the triarchic model (Patrick et al., 2009). Thus, the aim of the current study is to evaluate the extent to which traits included in the triarchic psychopathy model may predict conventional, self-realization, and hedonistic values.

Meanness includes callous disregard for others, lack of empathy, lack of close personal relationships, aggressive competitiveness and strategic exploitation of others for gain (Patrick et al., 2009; Drislane \& Patrick, 2016). Given that both conventional and self-realization values include constructive attitude towards others and the society as a whole, with conventional values including harmonious and honest life and helping others, and self-realization values including positive close and intimate relationships, we expect that meanness would be negatively related to both conventional and self-realization values. 
Consistent with the notion that meanness entails destructive excitement seeking, egocentrism, selfishness, and excitement seeking through destructiveness (Patrick et al., 2009), we expect that meanness would be positively related to hedonistic values. In summary, we expect that meanness would be negatively related to conventional and self-realization values, and positively to hedonistic values in both men and women sample (Hypothesis 1).

On the basis of the theoretical description that boldness entails thrilladventure seeking, audacity, and fearless dominance (Patrick et al., 2009), and that hedonism includes the main value to get pleasure, we expect that boldness would be positively related to hedonistic values in both men and women sample (Hypothesis 2).

On the basis of the theoretical description that disinhibition entails insistence on immediate gratification, deficient behavioural restraint and addictive behaviours of varying sorts (Patrick et al., 2009), we expect that disinhibition would be positively related to hedonistic values, in both men and women sample (Hypothesis 3 ).

As we did not have any a priori hypotheses regarding the relations between disinhibition and boldness with conventional and self-realization values, these analyses were considered exploratory. We also approached gender differences in psychopathy-value relationship in an exploratory way, since there is no clear theoretical underpinning or empirical basis to state an a priori hypothesis, although it might be generally expected that gender would moderate at least some of the relationship between psychopathic traits and values, based on the literature showing the moderating effect of gender (Sica et al., 2015). In other words, we approach the gender differences as a research question: Do relationships between TriPM psychopathic traits and values differ across gender?

\section{Method}

\subsection{Participants}

The study comprised a convenience sample of 396 (180 male and 216 female) undergraduate students (55\% female), aged from 18 to 45 years $(M=23.06, S D=5.15)$. Students attended various faculties and colleges located at Zagreb, the capital city of Croatia. Thus, students with different majors participated (46\% mathematics and physics, $16 \%$ criminalistics, $14 \%$ financing and law, 13\% kinesiology, $11 \%$ forestry).

\subsection{Procedure}

Students were approached by the researchers during regularly-scheduled classes and were provided with information about the purpose and procedure of the study. Participation was anonymous and voluntary and no incentives 
were given. After providing an informed consent, participants were given the questionnaires. The completion of the questionnaire typically took less than 30 minutes.

\subsection{Measures}

Triarchic Psychopathy Measure (TriPM, Patrick, 2010). TriPM is a nonproprietary 58-item self-report measure constructed to measure triarchically conceptualized psychopathy (Patrick et al., 2009), which yields scores on three subscales of Boldness, Meanness, and Disinhibition, as well as a Total Psychopathy score. Items are scored using a 4-point Likert-type scale: False $=0$, Somewhat False $=1$, Somewhat True $=2$, and True $=3$. Substantial research has accumulated in support of the construct validity and reliability of the TriPM, (e.g. Sellbom \& Phillips, 2013; Drislane et al., 2014; Drislane \& Patrick, 2016), including the Croatian version (Sokić \& Ljubin, 2014). In the current study, alpha coefficients for Boldness, Meanness, and Disinhibition scores were $.78, .84$, and .81 respectively, being highly similar to the alphas found in North American college students (cf. Sellbom \& Phillips, 2013).

Value Orientation Scale (VOS, Franc, Šakić, \& Ivčić, 2002). VOS was used for assessing values. It consists of 18 values and distinguishes three core value orientations (VO): Self-realization orientation (5 items, e.g. Doing what you like and what allows you to create something new; Doing something in which you could realize your ability and interests); Conventional orientation (6 items, e.g. Have a good education and acquire new knowledge; To live in harmony with one's own family and friends; To be honest and to live in accordance with one's moral principles) and Hedonistic orientation (7 items, e.g. Have good earning and high standard of living; Cater to and entertain as I want; Experience a lot of excitement). The respondents assessed the importance of each value as a guiding principle in their lives using a 5-point Likert-type scale ranging from 1 (not important at all) to 5 (very important). The internal consistency (alpha) reliabilities were. 70 for the Conventional, .66 for the Self-realization, and .75 for Hedonistic values.

\section{Results}

\subsection{Descriptive statistics and correlation analyses}

Descriptive statistics and gender differences in mean scores are shown in Table 1. All scales demonstrated an adequate range and internal psychometric characteristics in terms of reliability. In line with a previous study on adolescents (Franc et al., 2002), both men and women reported the highest self-realization value orientation, and the lowest hedonistic orientation 
(repeated measure analysis for men sample resulted in Wilks' lambda $=.31$, $p<.001$, partial $\eta^{2}=.69$; for women sample, Wilks' lambda $=.28, p<.001$, partial $\eta^{2}=.73$; differences between all groups were significant at $\left.p<.001\right)$.

In accordance with previous findings (e.g. Drislane \& Patrick, 2016), Meanness showed moderate correlation with Boldness and Disinhibition $(r s=$ .24 and $.52, p<0.01$ ), while Boldness and Disinhibition were not significantly correlated $(r=-.11, p>0.01)$.

Table 1. Descriptive statistics for TriPM Scales and

Value Orientation Scales in Men $(n=180)$ and Women $(n=216)$

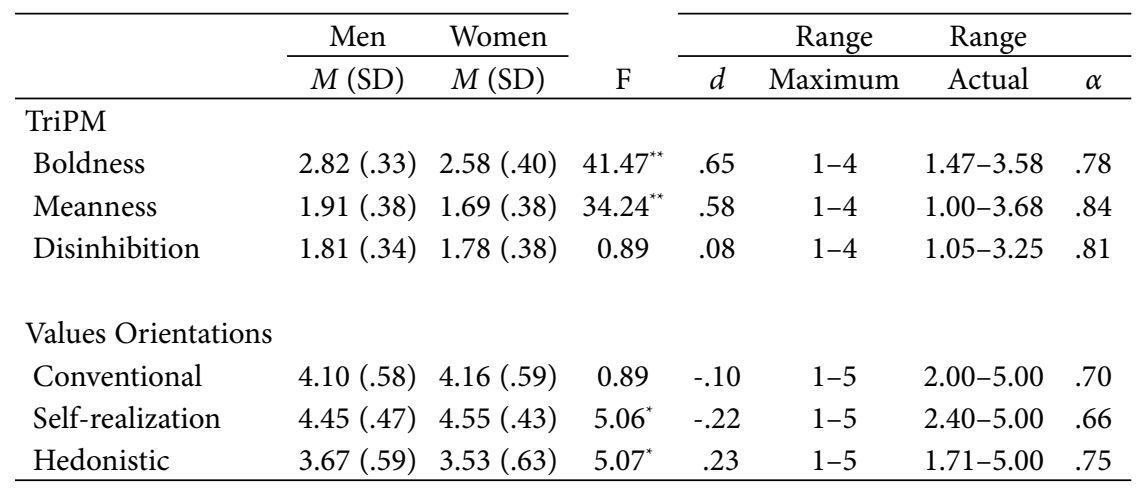

Note: $d=$ Cohen's d index. According to Cohen's (1988) interpretation of effect size, effect sizes around 0.2 are considered small, 0.5 medium, and 0.8 large. $\alpha=$ Cronbach's $\alpha$ calculated for total sample $(\mathrm{n}=396)$. For easier interpretation, descriptives pertain to mean item scores per composite scale. ${ }^{* *} p<.01,{ }^{*} p<.05$.

To compare men and women in the mean level of psychopathic traits and values, a one-way MANOVA was used. The combined DVs were significantly affected by gender (Wilks' lambda $=.004, \mathrm{~F}(6,389)=14356.78, p<.001$ ). TriPM Boldness and Meanness were significantly higher in men as compared to women, while there were no gender differences in the Disinhibition level, in line with previous studies (e.g. Drislane \& Patrick, 2016). With respect to value orientations, women reported higher self-realization values and lower hedonistic values, in accordance with previous research showing that men exhibited higher hedonistic and lower relativistic sexual values than females (Abraham \& Rahardjo, 2015), and similar to research which reported higher achievement, power and stimulation in men, and higher universalism (e.g., social justice, equality), and benevolence (e.g., helpfulness, loyalty) in women (Kajonius et al., 2015).

To explore possible gender differences in psychopathy-values relationships, three hierarchical regression analyses were performed, with value domains as criteria. In all models, the scores on psychopathy facets scores (Boldness, Meanness, Disinhibition), gender and age were included together as predictors in Step 1, and the three Gender x Facets interactions were entered 
in Step 2. A significant increase in $R^{2}$ in the second step would indicate gender differences in the relationship between the criterion and psychopathy facets. The results have shown that there was a significant increase in $R^{2}$ in the second step of analysis for hedonism $\left(R^{2} \Delta=0.021, F \Delta=3.14, p<.05\right)$, with significant interaction between gender and Disinhibition $(p<.01)$, suggesting that the association between the TriPM and this value differed across gender. Therefore, subsequent correlation and regression analyses were performed for men and women separately.

First, we present the zero-order correlations and partial correlations (controlling for two other TriPM components) between psychopathic components and value orientations in Table 2.

Table 2. Relations of TriPM components with Value Orientation Scales: Zero-order Correlations and Partial Correlations in Men $(n=180)$ and Women $(n=216)$.

\begin{tabular}{lcccccc}
\hline & \multicolumn{4}{c}{ Value Orientations } \\
& \multicolumn{2}{c}{ Conventional } & \multicolumn{2}{c}{ Self-realization } & \multicolumn{2}{c}{ Hedonistic } \\
\hline \multirow{2}{*}{ TriPM } & Men & Women & Men & Women & Men & Women \\
\hline Boldness & $\mathrm{r} / \mathrm{r}_{\mathrm{p}}$ & $\mathrm{r} / \mathrm{r}_{\mathrm{p}}$ & $\mathrm{r} / \mathrm{r}_{\mathrm{p}}$ & $\mathrm{r} / \mathrm{r}_{\mathrm{p}}$ & $\mathrm{r} / \mathrm{r}_{\mathrm{p}}$ & $\mathrm{r} / \mathrm{r}_{\mathrm{p}}$ \\
Meanness & $.03 / .06$ & $.09 / .16^{*}$ & $.09 / .10$ & $.04 / .07$ & $.17^{*} / .12$ & $.18^{* *} / .17^{*}$ \\
Disinhibition & $-.41^{* *} /-.33^{* *}$ & $-.31^{* *} /-.28^{* *}$ & $-.27^{* *} /-.17^{* *}$ & $-.18^{* *} /-.14^{*}$ & $.28^{* *} / .29^{* *}$ & $.33^{* *} / .16^{*}$ \\
\hline
\end{tabular}

Note. $r=$ Pearson's correlation. $r_{p}=$ partial correlation controlling for two other TriPM components. ${ }^{* *} p<.01,{ }^{*} p<.05$. Subscript letters indicate significant differences across gender.

As expected, in both men and women, Meanness showed an independent negative relationship with the conventional $\left(r_{p}=-.33, p<.001\right.$ and $r_{p}=.28$, $p<.001)$ and self-realization values $\left(r_{p}=-.17, p<.05\right.$ and $\left.r_{p}=-.14, p<.05\right)$, and an independent positive relationship with hedonistic values $\left(r_{p}=.29\right.$, $p<.001$ and $\left.r_{p}=.16, p<.05\right)$, thus supporting Hypothesis 1 . As expected, Boldness showed an independent positive relationship with hedonistic values $\left(r_{p}=.17, p<.05\right)$, but only in women sample. Thus, Hypothesis 2 was partially supported. Boldness also showed a low independent positive relationship with conventional values $\left(r_{p}=.16, p<.05\right)$ only in women sample. In men sample, Boldness showed no independent association with any value. Disinhibition showed negative bivariate relationships with self-realization and conventional values, but the relationship (as shown by partial $r$ ) was not significant after controlling for two other TriPM components, thus showing that the relationships were due to the variance shared with these two other components. As expected, Disinhibition demonstrated an independent relationship with hedonistic values, but only in women sample $\left(r_{p}=.17, p\right.$ $<.05)$. In men, no independent relationship was shown between Disinhibition and any value orientation. Thus, Hypothesis 3 was partially supported. 


\subsection{Predicting Values From Psychopathy Domain Scores}

To evaluate the distinctive contributions of the psychopathy facets and their interactions to the domains of values, we performed six regression analyses for each gender with the TriPM psychopathy facets (Boldness, Meanness, Disinhibition), included together as predictors in Step 1, and the interactions between psychopathy facets entered in Step 2. The criterion variables were particular values (conventional, self-realization, hedonistic). Age was included as the control variable in all regressions. The results are presented in Table 3.

Table 3. Hierarchical Regression Analyses with TriPM components as Predictors of Values Orientations in Men $(n=180)$ and Women $(n=216)$.

\begin{tabular}{|c|c|c|c|c|c|c|}
\hline & \multicolumn{6}{|c|}{ Value Orientations } \\
\hline & \multicolumn{2}{|c|}{ Conventional } & \multicolumn{2}{|c|}{ Self-realization } & \multicolumn{2}{|c|}{ Hedonistic } \\
\hline & Men & Women & Men & Women & Men & Women \\
\hline \multicolumn{7}{|l|}{ Step 1} \\
\hline Boldness & .06 & $.19^{* *}$ & -.11 & .10 & .12 & $.18^{*}$ \\
\hline Meanness & $-.38^{* *}$ & $-.36^{* *}$ & $-.25^{* *}$ & $-.20^{*}$ & $.33^{* *}$ & $.18^{*}$ \\
\hline Disinhibition & -.07 & .01 & -.14 & -.02 & -.15 & $.20^{*}$ \\
\hline$R^{2}$ & $.18^{* *}$ & $.13^{* *}$ & $.17^{* *}$ & $.06^{* *}$ & $.12^{* *}$ & $.15^{* *}$ \\
\hline \multicolumn{7}{|l|}{ Step 2} \\
\hline Boldness & .01 & $.22^{* *}$ & .07 & .11 & .11 & $.21^{* *}$ \\
\hline Meanness & $-.36^{* *}$ & $-.34^{* *}$ & $-.22^{*}$ & $-.20^{*}$ & $.31^{* *}$ & $.20^{*}$ \\
\hline Disinhibition & .03 & -.03 & -.02 & .04 & -.17 & $.20^{*}$ \\
\hline Boldness x Meanness & .14 & .10 & .11 & -.03 & .07 & .09 \\
\hline Boldness x Disinhibition & $-.18^{*}$ & -.06 & $-.19^{*}$ & -.09 & .01 & .00 \\
\hline Meanness x Disinhibition & -.16 & .03 & $-.19^{*}$ & -.13 & .05 & -.02 \\
\hline$\Delta R^{2}$ & $.05^{\star}$ & .01 & $.05^{* *}$ & .01 & .01 & .01 \\
\hline$R^{2}$ & $.23^{* *}$ & $.14^{* *}$ & $.23^{* *}$ & $.08^{*}$ & $.13^{* *}$ & $.16^{* *}$ \\
\hline \multicolumn{7}{|c|}{$\begin{array}{l}\text { Overall, the multiple regression analysis has shown that the TriPM } \\
\text { ychopathy components together explained from } 13 \text { to } 23 \% \text { of variance in } \\
\text { lue orientations in men, and from } 8 \text { to } 16 \% \text { of variance in value orientations } \\
\text { women. More specifically, in men sample the TriPM components together } \\
\text { plained } 23 \% \text { of the variance in conventional values }(R=0.47, F[7,172]= \\
13, p<.001), 23 \% \text { of self-realization values variance }(R=.48, F[7,172]= \\
21, p<.001) \text {, and } 13 \% \text { of variance in hedonistic values }(R=.36, F[7,172]= \\
55, p<.01) \text {. In women, the TriPM components were the strongest predictors } \\
\text { hedonistic values, explaining } 16 \% \text { of variance }(R=.39, F[7,208]=5,45, p \\
001) \text {, followed by the } 14 \% \text { of variance explained in conventional values }(R \\
.37, F[7,208]=4.73, p<.001) \text {, and } 8 \% \text { in self-realization values }(R=.28 \text {, } \\
7,208]=2.45, p<.05) \text {. }\end{array}$} \\
\hline
\end{tabular}


As expected, for both men and women, Meanness uniquely predicted conventional $(\beta=-.36$ and -.34 , respectively, both $p<.001)$, self-realization $(\beta=-.22$ and -.20 , respectively, both $p<.05)$, and hedonistic values $(\beta=.31$ $p<.01$ and $\beta=.20, p<.05$, respectively). However, some relations between TriPM components and values were moderated by gender. Boldness uniquely predicted conventional $(\beta=.22, p<.01)$ and hedonistic $(\beta=.21, p<.01)$ values only in women. Disinhibition uniquely predicted the hedonistic orientation $(\beta=.20, p<.05)$ only in women, whereas the scores on Disinhibition were unrelated to hedonism in men.

Several interaction effects between the TriPM components in predicting value orientations also emerged only in men. Boldness was found to moderate the relationship between disinhibition and self-realization, as well as between disinhibition and conventional value orientations. On the high level of boldness, the negative relationship of disinhibition with conventional and self-realization values was more pronounced (see Figure 1 and 2). Meanness moderated the relationship between disinhibition and self-realization value orientation. On the high level of meanness, disinhibition showed a negative effect on self-realization, while the opposite trend could be seen on the low meanness level (see Figure 3).

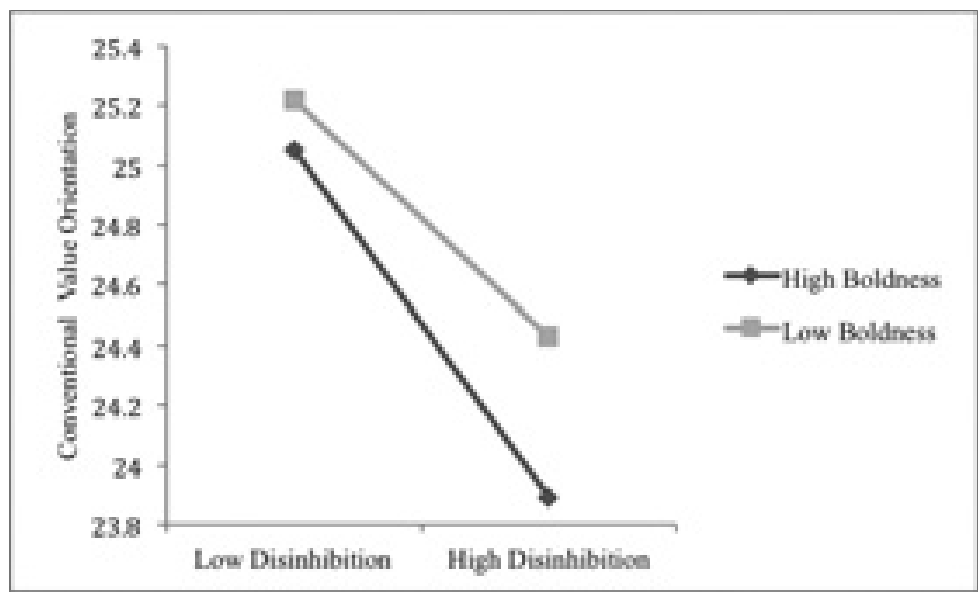

Figure 1. Interaction of Boldness moderating the effect of Disinhibition on Conventional Value Orientation. 


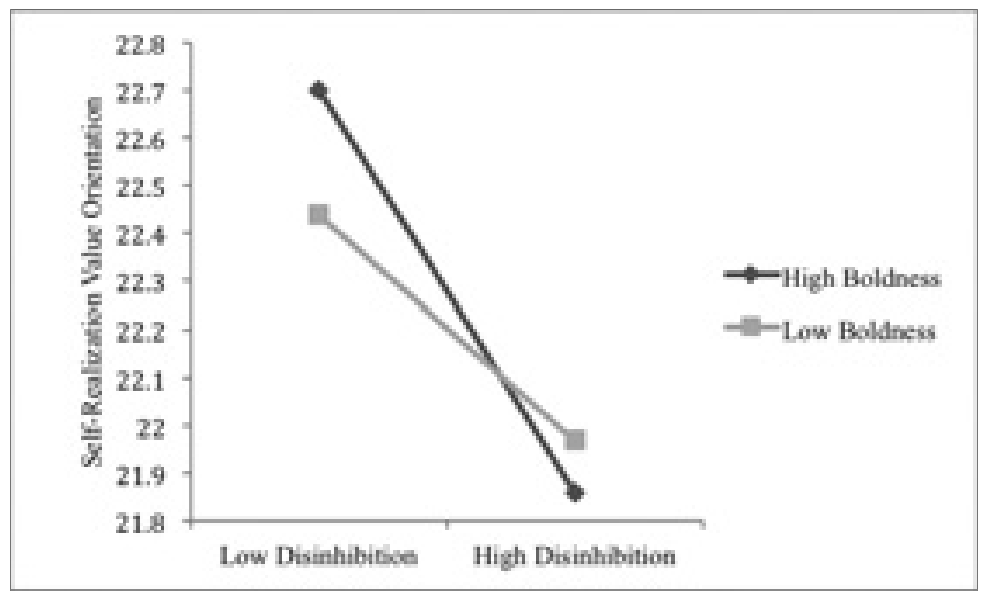

Figure 2. Interaction of Boldness moderating the effect of Disinhibition on Self-Realization Value Orientation.

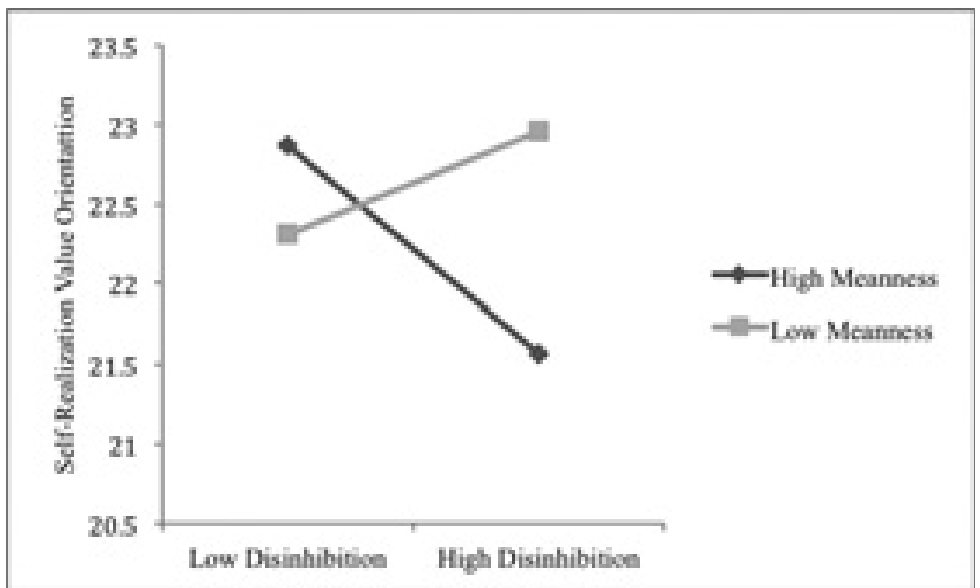

Figure 3. Interaction of Meanness moderating the effect of Disinhibition on Self-Realization Value Orientation.

\section{Discussion and conclusions}

In general, the results of the study confirmed the triarchic psychopathy- values relationships and suggested that psychopathic personality traits are an important predictor of acquisition of certain values. Overall, triarchic psychopathy traits predicted from 13 to $23 \%$ of variance in specific values of men, and from 8 to $16 \%$ of variance in the values of women.

As predicted, in both genders, meanness was independently and negatively associated with conventional and self-realization values and positively with 
hedonistic values. Conventional values were associated to social responsibility, traditionalism and morality, while self-realization values captured the realization of close intimate and friendly relations (Franc et al., 2002). The lack of the morality, a tendency to exploit others and disregard for the rights of others, are some of the core characteristics of psychopathy (Glenn et al., 2010; Sellbom \& Phillips, 2013; Blair, Peschardt, Budhani, Mitchell, \& Pine, 2006), which may incline persons with psychopathic traits not to adopt these values. On the other hand, selfishness and greed for power embodied in psychopathy incline them towards hedonistic values encompassing the values of enjoying life, a high standard of living, pleasure and sensuous gratification for oneself, social prestige, control and dominance over people. The finding of the positive relationship of meanness with hedonistic values and the negative relationship with conventional values is in line with previous studies showing that psychopathy is positively correlated with hedonistic values (Kajonius et al., 2015; Abraham \& Rahjardo, 2015) and negatively with the values such as collective interests and self-transcendence (Jonason et al., 2015). It is also in line with the studies showing that hedonistic and non-conventional value orientations are associated with an inclination towards an aggressive and egocentric pattern of behaviour (Vlah, Lončarić, \& Tatalović Vorkapić, $2011 \mathrm{~b}$ ), the same pattern which is a characteristic of psychopaths.

Our results showed that meanness was most consistently related to values across gender (positively with hedonistic values, and negatively with conventional values). On the other hand, the relationship of boldness and disinhibition with values was moderated by gender. This is in accordance with the emerging evidence which suggests that there may be some gender differences in the relation among the TriPM components and different external criteria (Drislane \& Patrick, 2016).

More specifically, along with meanness, boldness and disinhibition showed predictive power for endorsing hedonistic value orientations in women, while in men it was only meanness which was predictive for the hedonistic value orientation. It may be the case that there is a gendered based social inhibition against the acceptance of hedonistic values, with women being more socially disapproved of while having hedonistic values. The fact that both boldness (reflecting thrill-adventure seeking) and disinhibition (reflecting deficient behavioural restraint) are manifested as an inclination towards hedonistic values only in women is in line with such an interpretation, suggesting that these two components of psychopathy at low values have the role of the protector for (not) adopting socially risky values in women, while high boldness and the lack of inhibition route the secondary track for adopting hedonistic values. For men, boldness and disinhibition were not predictive for adopting hedonistic values. On the other hand, as suggested by the results, the role of meanness is different from the role of boldness and inhibition, 
with meanness acting as a fuel, being directly routed to adopting socially risky values in both men and women.

There were also some gender differences in respect to the relationship between the triarchic psychopathy components and conventional values. In women, adopting lower conventional value orientations was explained both by low boldness and high meanness. In men, lower conventional value orientations were directly (negatively) related only to meanness, while there was no direct effect of boldness. Instead, boldness acted as a moderator, increasing the negative effect of disinhibition under the high boldness condition.

Additionally, only in men, two interactions between the TriPM components also emerged as significant predictors of self-realization values. First, similarly to the interaction found between boldness and disinhibition in predicting conventional values, it was found that the negative effect of disinhibition on self-realization values was more pronounced under the high boldness condition. Thus, it seems that that boldness has a synergistic effect on disinhibition in predicting both low conventional and self-realization value orientations, acting as an amplifier of the negative effect of disinhibition. Second, it was found that only under the high meanness conditions, the negative effect of disinhibition on the acquisition of self-realization values emerged, while the opposite trend emerged for low meanness condition (i.e. a positive association of disinhibition with self-realization values). Thus, for men's self-realization values, meanness has a somewhat different and more complex role, showing both the direct negative effect and also acting as a necessary condition for expressing the negative effect of disinhibition.

There is a discussion on whether boldness features represent a different pathway to maladaptive behaviour or a protective factor with respect to prosocial outcomes (Drislane et al., 2014; Lilienfeld et al., 2015). In the present study, boldness showed positive association both with hedonistic and with conventional values in women sample only. In men sample, there was no direct effect of boldness on any value, but the interactions suggested that boldness amplifies the negative effect of disinhibition for lower acquisition of conventional and self-realization values. Bearing in mind that the acquisition of conventional values is socially adaptive, and the acquisition of hedonism is related to socially risky and maladaptive behaviours, such as aggressive conflict management and delinquency (Romero et al., 2001; Franc et al., 2002), the association of boldness both with conventional and hedonistic values in women is in line with previous studies showing that boldness is both associated with indices of adaptive function, but also with psychological maladjustment, including aggression (Fanti, Kyranides, Drislane, Colins, \& Andershed, 2016), lack of altruism and erratic lifestyle (Drislane \& Patrick, 2016). Thus, our results suggest that in women boldness has both an adaptive 
and maladaptive function. On the other hand, in men, boldness has only a maladaptive function, but this is less pronounced in comparison to women, since boldness has a moderating function, and is not directly related to socially risky values (hedonism). Overall, the results are in line with the view that boldness is not purely an adaptive component of psychopathy (Drislane et al., 2014), and that the adaptive role of boldness in defining psychopathy is highly controversial (Drislane \& Patrick, 2016).

The fact that psychopathy explained more variance in conventional and self-realization value orientations in men than in women $(23 \%$ vs. $14 \%$ for conventional VO, and $23 \%$ vs. $8 \%$ for self-realization $\mathrm{VO}$ ) may suggest that psychopathic personality traits have a more important role in men than in women in the acquisition of (low) conventional and (low) self-realization values.

Overall, our results point to the central role of meanness in psychopathy - values relationship. The results also showed that gender has some moderating role in the disinhibition/boldness and values relationship, although it should be noted that gender differences in these relations were small.

There are several limitations to this study that need to be acknowledged. First, the participants consisted of a homogenous sample of students rather than offenders or clinical patients. For these reasons, further research is needed to evaluate the generalizability of findings to correctional or clinicalforensic samples. Additionally, further studies may use other measures of triarchically conceptualized psychopathy, as well as other measures of values to corroborate the findings.

\subsection{Conclusion}

In this study, we demonstrated the link between Patrick et al's (2009) triarchically conceptualized psychopathic traits, and value orientations (Franc et al., 2002). The results were consistent with the proposed direct relationship of meanness with all three values studied, but the proposed relationship between boldness and disinhibition with hedonistic values was found only in women.

\section{References}

Abraham, J., Rahardjo, W. (2015). Psychopathy, sexual values dimensions, and premarital sexual behaviour among urban unmarried adolescents. Procedia - Social and Behavioral Sciences, 165, 2-11. doi:10.1016/j.sbspro.2014.12.598

Bilsky, W., Schwartz, S. H. (1994). Values and personality. European Journal of Personality, 8, 163-181.

Blair, R. J. (2010). Neuroimaging of psychopathy and antisocial behavior: a targeted review. Current Psychiatry Reports, 12(1), 76-82. doi: 10.1007/s11920-009-0086-x 
Blair, R. J., Peschardt, K.S., Budhani, S., Mitchell, D.G., Pine, D.S. (2006). The development of psychopathy. Journal of Child Psychology and Psychiatry, 47, 262-76. doi:10.1111/j.1469-7610.2006.01596.x

Blagov, P. S., Patrick, C. J., Oost, K. M., Goodman, J. A., \& Pugh, A. T. (2016). Triarchic psychopathy measure: validity in relation to normal-range traits, Personality pathology, and psychological adjustment. Journal of Personality Disorders, 30, 71-81. doi:10.1521/pedi_2015_29_182

Buckels, R. E., Trapnell, P. D., \& Paulhus, D. L. (2014). Trolls just want to have fun. Personality and Individual Differences, 67, 97-102. doi:10.1016/j.paid.2014.01.016

Cleckley, H. M. (1976). The mask of sanity (5th ed.). St. Louis, MO: Mosby. (Original edition published 1941)

de Vogel, V., \& Lancel, M. (2016). Gender differences in the assessment and manifestation of psychopathy: Results from a multicenter study in forensic psychiatric patients. International Journal of Forensic Mental Health, 15(1), 97-110. doi:10.1 080/14999013.2016.1138173

Drislane, L. E., \& Patrick, C. J. (2016). Integrating alternative conceptions of psychopathic personality: A latent variable model of triarchic psychopathy constructs. Journal of Personality Disorders, 30, 1-23. doi:10.1521/pedi_2016_30_240

Drislane, L. E., Patrick, C. J., \& Arsal, G. (2014). Clarifying the content coverage of differing psychopathy inventories through reference to the Triarchic Psychopathy Measure. Psychological Assessment, 26(2):350-362. doi:10.1037/a0035152

Fanti, K. A., Kyranides, M. N., Drislane, L. E., Colins, O. F., \& Andershed, H. (2016). Validation of the Greek Cypriot translation of the Triarchic psychopathy measure. Journal of Personality Assessment, 98, 146 -154. doi:10.1080/00223891.201 5.1077452

Franc, R., Šakić, V., Ivičić, I. (2002). Vrednote i vrijednosne orijentacije adolescenata: hijerarhija i povezanost sa stavovima i ponašanjima. Društvena istraživanja, 11(2-3), 215-238.

Glenn, A. L., Koleva, S., Iyer, R., Graham, J., \&. Ditto, P.H. (2010). Moral identity in psychopathy. Judgment and Decision Making, 5, (7), 497-505.

Hare, R. D. (2003). The Hare Psychopathy Checklist - revised ( $2^{\text {nd }}$ ed.). Toronto, Ontario, Canada: Multi-Health Systems.

Jonason, P. K., Strosser, G. L., Kroll, C. H., Duineveld, J. J., \& Baruffi, S. A. (2015). Valuing myself over others: The Dark Triad traits and moral and social values. Personality and Individual Differences, 81, 102-106. doi:10.1016/j.paid.2014.10.045

Kajonius, P., Persson, B., \& Jonason, P.K. (2015). Hedonism, achievement, and power: Universal values that characterize the Dark Triad. Personality and Individual Differences, 77, 173-178. doi:10.1016/j.paid.2014.12.055

Levenson, M. R., Kiehl, K. A., \& Fitzpatrick, C. M. (1995). Assessing psychopathic Attributes in a noninstitutionalized population. Journal of Personality and Social Psychology, 68(1),151-158.

Lilienfeld, S. O., Smith, S. F., Sauvigné, K. C., Patrick, C. J., Drislane, L. E., Latzman, R. D., \& Krueger, R. F. (2015). Is boldness relevant to psychopathic personality? Meta-analytic relations with non-psychopathy checklist-based measures of 
psychopathy. Psychological Assessment. Advance online publication. doi:10.1037/ pas0000244.

Marion, B. E., Sellbom, M., Salekin, R. T., Toomey, J. A., Kucharski, L. T., \& Duncan, S. (2012). An examination of the association between psychopathy and dissimulation using the MMPI-2-RF validity scales. Law and Human Behavior. Advance online publication. doi:10.1037/lhb0000008

Martin, A. L. (1985). Values and personality: a survey of their relationship in the case of juvenile delinquence. Personality and Individual Differences, 6(4), 519-522.

Miller, J. D., Watts, A., \& Jones, S. E. (2011). Does psychopathy manifest divergent relations with components of its nomological network depending on gender? Personality and Individual Differences, 50, 564-569. doi: 10.1016/j.paid.2010.11.028

Parks-Leduc, L., Feldman, G., \& Bardi, A. (2015). Personality traits and personal values: A meta-analysis. Personality and Social Psychology Review. 15, 3-19. doi:10.1177/1088868314538548.

Patrick, C. J. (2010). Operationalizing the triarchic conceptualization of psychopathy: Preliminary description of brief scales for assessment of boldness, meanness, and disinhibition. Unpublished manual, Department of Psychology, Florida State University, Tallahassee. Retrieved from http://www.phenxtoolkit.org

Patrick, C. J., Drislane, L. E., \& Strickland, C. D. (2012). Conceptualizing psychopathy in triarchic terms: Implications for treatment. International Journal of Forensic Mental Health, 11, 253-266. doi:10.1080/14999013.2012.746761

Patrick, C. J., Fowles D. C., Krueger, R. F. (2009). Triarchic conceptualization of psychopathy: Developmental origins of disinhibition, boldness, and meanness. Development and Psychopathology, 21, 913-938. doi:10.1017/S0954579409000492

Poy, R., Segarra, P., Esteller, À., López, R., \& Moltó, J. (2014). FFM description of the triarchic conceptualization of psychopathy in men and women. Psychological Assessment, 26, 69-76. doi:10.1037/a0034642

Roccas, S., Sagiv, L., Schwartz, S. H., \& Knafo, A. (2002). The Big Five personality factors and personal values. Personality \& Social Psychology Bulletin, 28, 789-801.

Rokeach, M. (1973). The Nature of Human Values, New York: Free Press.

Romero, E., Sobral, J., Luengo, M. A. i Marzoa, J. A. (2001). Values and Antisocial Behaviour among Spanish Adolescents. Journal of Genetic Psychology, 162(1), 20-40. doi:10.1080/00221320109597879

Schwartz, S. H. (1992). Universals in the content and structure of values: Theoretical advances and empirical tests in 20 countries. In M. Zanna (Ed.), Advances in experimental social psychology (Vol. 25, pp. 1-65). New York: Academic Press.

Schwartz, S, H. (1994): Are there universal aspects in the content and structure of values?, Journal of Social Issues, 50, 19-45.

Schwartz, S. H., \& Bilsky, W. (1990). Toward a Theory of the universal content and structure of values, extension and cross-cultural replications, Journal of Personality and Social Psychology, 58, 878-891.

Sellbom, M., Donnelly, K. M., Rock, R. C., Phillips, T. R., \& Ben-Porath, Y. S. (2016). Examining gender as moderating the association between psychopathy and $\mathrm{s} \mathrm{u}-$ bstance abuse. Psychology, Crime \& Law. Advance online publication. doi:10.108 0/1068316X.2016.1258466 
Sellbom, M., \& Phillips, T. R. (2013). An examination of the triarchic conceptualization of psychopathy in incarcerated and nonincarcerated samples. Journal of Abnormal Psychology, 122, 208-214. doi:10.1037/a0029306

Sevecke, K., Lehmkuhl, G., Krischer, M. K. (2009). Examining relations between psychopathology and psychopathy dimensions among adolescent female and male offenders. European Child and Adolescent Psychiatry, 18(2), 85-95. doi: $10.1007 / \mathrm{s} 00787-008-0707-7$

Sica, C., Drislane, L., Caudek, C., Angrilli, A., Bottesi, G., Cerea, S., \& Ghisi, M. (2015). A test of the construct validity of the triarchic psychopathy measure in an Italian community sample. Personality and Individual Differences, 82, 163168. doi:10.1016/j.paid.2015.03.015

Silfver, M., Helkama, K., Lönnqvist, J. E., \& Verkasalo, M. (2008). The relation between value priorities and proneness to guilt, shame, and empathy. Motivation and Emotion, 32, 69-80. doi:10.1007/s11031-008-9084-2.

Sokić, K., \& Ljubin Golub, T. (2014, May). Validation of the Triarchic Model of psychopathy within Hexaco Model of Personality. Poster presented at the conference 19th Psychology Days in Zadar, Croatia, 29 - 31 May, 2014. Paper summaries, pp. 221.

Stanley, J. H., Wygant, D. B., \& Sellbom, M. (2013). Elaborating on the construct validity of the Triarchic Psychopathy Measure in a criminal offender sample. Journal of Personality Assessment, 95, 343-350. doi: 10.1080/00223891.2012.735302

Strand, S., \& Belfrage, H. (2005). Gender differences in psychopathy in a Swedish offender sample. Behavioral Sciences \& The Law, 23(6), 837-850.

Verona, E., \& Vitale, J. (2006). Psychopathy in women: Assessment, manifestations, and etiology. In C. J. Patrick (Ed.), Handbook of the psychopathy (pp. 415-436). New York, NY: Guilford Press.

Vlah, N., Lončarić, D., \& Tatalović Vorkapić, S., (2011b). Vrijednosne orijentacije učenika strukovnih škola kao prediktori obrazaca ponašanja u socijalnim sukobima (Vocational school students' value orientations as predictors of behavioral patterns in social conflicts). Hrvatska revija za rehabilitacijska istraživanja, 47(1), 31-40. 